\title{
ECHOCARDIOGRAPHIC ASSESSMENT OF RIGHT VENTRICULAR FUNCTION AFTER SUCCESSFUL REVASCULARIZATION FOR ACUTE ANTERIOR MYOCARDIAL INFARCTION WITHOUT RIGHT VENTRICULAR INFARCTION
}

By

\section{Mohamed El-Sayed Hammad, Mohamed Sami Abd El-Samea and Abd El-Mohsen Mostfa}

\author{
Department of Cardiology, Faculty of Medicine, Al-Azhar University, Cairo, Egypt \\ Corresponding author: Mohamed El-Sayed Hammad \\ E-mail: ma102416@gmail.com
}

\begin{abstract}
Background: Right ventricular (RV) affection in acute left ventricular (LV) myocardial infarction (MI) is frequently underestimated in the clinical setting as the diagnostic limitations of the electrocardiogram and echocardiography.

Objective: To assess RV function in patients presented with first acute anterior ST elevation myocardial infarction (STEMI) who underwent successful primary percutaneous coronary intervention (PCI) and factors affecting it.

Patients and Methods: Forty consecutive patients with anterior STEMI who underwent successful primary PCI in the Cathetrization (cath) labs of Al-Azhar University Hospitals, Cairo, Egypt from March 2019 to April 2020 for first acute anterior STEMI without RV were enrolled in the study. Presence of a coexisting clinical condition that might affect RV function, patients with RV infarction or those having significant stenosis $(>50 \%)$ affecting RV branch or right coronary artery proximal to RV branch were excluded. Echocardiography was performed during the hospital stay to assess the LV and RV systolic and diastolic functions with special focus on tricuspid annular plane systolic excursion, mid RV end-diastolic dimension, right atrial area, RV fractional area change, and tissue Doppler-derived myocardial performance index.
\end{abstract}

Results: RV dysfunction, according to our definition in the first anterior MI, occurred in (55\%) of the study population. Independent predictors for abnormal RV function were left circumflex artery mid or proximal affection, eventful procedure, occurrence of no reflow, glucose level, LV end-systolic dimension, LV enddiastolic dimension, and LV ejection fraction.

Conclusion: RV dysfunction is detected in anterior myocardial infarction after successful revascularization. Several echocardiographic parameters may be possible measures for RV dysfunction including RVFAC, TAPSI, MPI and S'.

Keywords: Acute myocardial infarction, Myocardial performance index, Right ventricle.

\section{INTRODUCTION}

Right ventricular (RV) involvement after an acute left ventricular (LV) myocardial infarction (MI) has been shown to be associated with higher morbidity and mortality. The prevalence of RV involvement in acute LV MI reportedly ranges from $50 \%$ to $80 \%$ in 
postmortem and animal studies but is frequently underestimated in the clinical setting owing to the diagnostic limitations of the electrocardiogram (ECG) and echocardiography (Jensen et al., 2010). Quantitative assessment of RV function is often difficult using the various noninvasive imaging modalities owing to the inherently complex geometry of the right ventricle (Hsu et al., 2013).

Echocardiography remains the most commonly used technique for $\mathrm{RV}$ function assessment in clinical practice because of its widespread availability. The myocardial performance index (MPI) of $\mathrm{RV}$ based on conventional Doppler echocardiography has been proven to be useful in the evaluation of RV function and recommended as one of the initial quantitative measurements of RV diastolic function and may be a sensitive tool for detecting "occult", RV dysfunction in acute LV MI (Hsu et al., 2013).

The aim of this study was to assess $\mathrm{RV}$ function in patients with successful primary percutaneous coronary intervention (PCI) for acute anterior ST elevation myocardial infarction (STEMI) without RV infarction and determine factors affecting it.

\section{PATIENTS AND METHODS}

The current study enrolled 40 patients who underwent successful primary PCI in the Cath labs of Al-Azhar University Hospitals, Cairo, Egypt from March 2019 to April 2020 for first acute anterior STEMI without RV infarction.

Inclusion criteria: All patients with the definite diagnosis of anterior STEMI as per the universal definition were enrolled. Patients underwent angiographically successful primary PCI defined as successful deployment of stent in culprit infarct related artery (IRA), no residual dissection, and less than $20 \%$ residual stenosis in IRA (Thygesen et al., 2012).

Exclusion criteria: Patients with any of the following criteria were excluded from the study:

1. Presence of RV infarction defined by an ST-segment elevation of $0.1 \mathrm{mV}$ or greater in lead V4R on ECG at presentation.

2. Previous history of MI or coronary revascularization.

3. Persistent hemodynamic instability necessity use of positive inotropes.

4. Atrial fibrillation.

5. Moderate or severe valvular heart disease.

6. Presence of a coexisting clinical condition that might affect RV function, including pericardial disease, chronic lung disease, pulmonary hypertension, or connective tissue disorder.

7. Patient with contraindication for coronary angiography such as severe renal impairment, coagulopathy, etc.

8. Patient with significant stenosis (>50\%) affecting RV branch or right coronary artery proximal to $\mathrm{RV}$ branch.

9. Consent refusal.

Patients who met the inclusion criteria were subjected to the following:

1. Thorough history taking.

2. Full clinical examination: Targeted physical examination data were 
recorded including general and local examination with special attention to vital data and signs suggestive of risk factor for coronary artery disease (CAD), mechanical complications, signs of heart failure, and Killip classification.

3. Twelve-lead surface ECG was performed on admission, 90 minutes after reperfusion, then every 8 hours in the first 24 hours, then daily thereafter to confirm the diagnosis of STEMI and to exclude the presence of $\mathrm{RV}$ infarction, and to follow up the ST segment resolution time.

4. Primary PCI after diagnostic coronary angiography, stenting with or without balloon predilation, then assessment of post procedure flow using thrombolysis in MI, i.e. TIMI.

5. Echocardiography was performed within 72 hours of successful reperfusion. I did a comprehensive 2D Doppler echocardiography and pulsedwave TDI while the patients were lying in the partial left lateral decubitus position during either shallow respiration or a breath hold:

1. The LV end-systolic dimension (LVESD) and end diastolic dimension (LVEDD) were obtained from M-mode recording, from the parasternal long axis view. The LV ejection fraction (LVEF) was estimated by M-mode in para strenal long axis view.

2. The 16-segment model for LV segmentation was used to evaluate regional wall motion abnormalities as recommended by the American
Society of echocardiography (Lang et al., 2005).

3. The RV end-diastolic dimension was assessed at the mid-cavity of the right ventricle in the apical four-chamber view.

4. The RV fractional area change (RVFAC) was calculated as the RV end-diastolic area- the endsystolic area/the RV end-diastolic area.

5. The right atrial area (RAA) was estimated by planimetry at the end of ventricular systole.

6. The tricuspid annular plane systolic excursion (TAPSE) was measured from the apical fourchamber view at the RV free wall level by placing an M-mode cursor passed through the tricuspid lateral annulus in apical four-chamber view, and measuring the amount of longitudinal displacement of the annulus at peak-systole.

7. The trans-mitral and -tricuspid Doppler flow velocities were recorded from the apical four chamber view with the sample volume placed between the tips of the mitral and tricuspid valves, respectively, and the peak early filling velocity (E), peak atrial velocity (A) were measured, and E/A ratio was calculated.

8. Pulsed-wave TDI images were acquired from the standard apical four chamber view, a 5.2-mm sample volume was placed at the lateral tricuspid annulus, mitral septal, and mitral lateral annar sites to obtain the spectral pulsed 
tissue Doppler data. Three cardiac cycles were averaged for each TDI measurement.

Peak systolic annular velocity (Str), early diastolic annular velocity (Etr), and late diastolic annular velocity (Atr) of the right ventricle were measured offline; and the Etr/Atr and E/Etr ratios were calculated. Isovolumic relaxation time (IVRT) was measured as the time interval from the end of Str to the onset of Etr, isovolumic contraction time (measured as the time interval from the end of the Atr to the beginning of the Str), and ejection time (measured from the onset to the end of Str) of the right ventricle were calculated to obtain the TDI derived RV MPI with the formula: IVRT+ isovolumic contraction time/ejection time. MPI was defined as an MPI $>\mathbf{0 . 5 5}$.

Patients were assigned as having abnormal RV function if they had a combination of at least two of: RVFAC $<35 \%$, RV MPI using TDI >0.55, TAPSE $<16 \mathrm{~mm}$ (Rudski et al., 2010).

\section{Statistical analysis:}

Data were analyzed using Statistical Package for the Social Science (SPSS) version 20. Quantitative data were expressed as mean \pm standard deviation (SD). Qualitative data were expressed as frequency and percentage. Comparisons were made between the two groups using $t$ test for continuous variables and Chisquare test. Difference was considered statistically significant when $p<0.05$.

\section{RESULTS}

The mean age of our patients was $55.85 \pm 9.2$ years old, $24(60 \%)$ were males, $(62.5 \%)$ were smokers, $30(75 \%)$ were diabetic, $30(75 \%)$ were hypertensive, $18(45 \%)$ were dyslipidemia, and $15(37.5 \%)$ had positive family history premature CAD.

Echocardiographic finding analysis showed that the mean EF $(43.15 \pm 9.39)$
LVESD was $(29.20 \pm 6.93) \mathrm{mm}$, LVEDD was $(53.10 \pm 3.14) \mathrm{mm}$, whereas mean LAD was $(36.93 \pm 2.53) \mathrm{mm}$.

With regard to $\mathrm{RV}$ function, the mean RVEDD was $29.50 \pm 3.04 \mathrm{~mm}$, RVFAC was $36.88 \pm 5.94 \%$, RAA was $19.98 \pm 1.64$ $\mathrm{cm} 2$, TAPSE was $18.78 \pm 4.88 \mathrm{~mm}$, MPI was $64.18 \pm 15.42$, and $S^{\prime}$ ratio was $9.22 \pm 0.77$ (Table 1). 
Table (1): Analysis of echocardiographic parameters

\begin{tabular}{|c|c|c|}
\hline \multicolumn{2}{|c|}{ Echocardiographic parameters } & Patients $(n=40)$ \\
\hline \multirow{2}{*}{ LAD (mm) } & Mean $\pm \mathrm{SD}$ & $36.93 \pm 2.53$ \\
\hline & Range & $31-42$ \\
\hline \multirow{2}{*}{ LV EDD (mm) } & Mean \pm SD & $53.10 \pm 3.14$ \\
\hline & Range & $48-59$ \\
\hline \multirow{2}{*}{ LV ESD (mm) } & Mean \pm SD & $29.20 \pm 6.93$ \\
\hline & Range & $3-41$ \\
\hline \multirow{2}{*}{ LV EDV (ml) } & Mean $\pm \mathrm{SD}$ & $99.10 \pm 18.04$ \\
\hline & Range & 60-139 \\
\hline \multirow{2}{*}{ LV ESV (ml) } & Mean \pm SD & $56.23 \pm 13.69$ \\
\hline & Range & $34-90$ \\
\hline \multirow{2}{*}{ LV EF (\%) } & Mean $\pm \mathrm{SD}$ & $43.15 \pm 9.39$ \\
\hline & Range & $25-57$ \\
\hline \multirow{2}{*}{$\begin{array}{l}\text { RV Dimensions } \\
(\mathrm{mm})\end{array}$} & Mean \pm SD & $29.50 \pm 3.04$ \\
\hline & Range & $21-35$ \\
\hline \multirow{2}{*}{ RAA $(\mathrm{cm})$} & Mean \pm SD & $19.98 \pm 1.64$ \\
\hline & Range & $17-24$ \\
\hline \multirow{2}{*}{ RVFAC (\%) } & Mean \pm SD & $36.88 \pm 5.94$ \\
\hline & Range & $30-50$ \\
\hline \multirow{2}{*}{ TAPSI (mm) } & Mean \pm SD & $18.78 \pm 4.88$ \\
\hline & Range & $13-29$ \\
\hline \multirow{2}{*}{$\operatorname{MPI}(\%)$} & Mean \pm SD & $64.18 \pm 15.42$ \\
\hline & Range & $49-94$ \\
\hline \multirow{2}{*}{$\mathrm{S}^{\prime}$} & Mean \pm SD & $9.22 \pm 0.77$ \\
\hline & Range & $8-11$ \\
\hline
\end{tabular}

Additionally, we found that in coronary angiography, LAD affection was about $32.5 \%$ in proximal segment, $45 \%$ in mid segment, $5 \%$ in proximal to mid part $12.5 \%$ in osteal segment, and 5\% multiple lesions, while LCX affection was about $40 \%$ in proximal part $17.5 \%$, mid part $22.5 \%$, and $60 \%$ non-significant lesion (Table 2).

Table (2): Data showing analysis of CA findings

\begin{tabular}{|c|c|c|}
\hline \multicolumn{2}{|c|}{ CA parameters } & Patients (n = 40) \\
\hline \multirow{4}{*}{ LAD lesion } & Proximal & $13(32.5 \%)$ \\
\cline { 2 - 3 } & Mid & $18(45 \%)$ \\
\cline { 2 - 3 } & Proximal to mid & $2(5 \%)$ \\
\cline { 2 - 3 } & Osteal & $5(12.5 \%)$ \\
\cline { 2 - 3 } & Multiple lesions & $2(5 \%)$ \\
\hline \multirow{3}{*}{ LCX lesion } & Prox & $7(17.5 \%)$ \\
\cline { 2 - 3 } & Mid & $9(22.5 \%)$ \\
\cline { 2 - 3 } & Non-significant lesion & $24(60 \%)$ \\
\hline \multirow{3}{*}{ DOMINANCE } & Yes & $10(25 \%)$ \\
\cline { 2 - 3 } & No & $26(65 \%)$ \\
\cline { 2 - 3 } & Co & $4(10 \%)$ \\
\hline \multirow{3}{*}{ PCI } & 1DES & $21(52.5 \%)$ \\
\cline { 2 - 3 } & 2DES & $17(42.5 \%)$ \\
\cline { 2 - 3 } & 3DES & $2(5 \%)$ \\
\hline
\end{tabular}


According to RV function assessment by echocardiography patients were classified into two groups: Group 1 ( $n=$ 22) had impaired RV function, and Group $2(n=18)$ with normal RV function. By analysis and comparison of collected data, there were no difference in terms of Age
$(\mathrm{P}$ value $=0.938)$, gender $(\mathrm{P}$ value $=$ $0.436)$, diabetes mellituss $(\mathrm{DM})(\mathrm{P}$ value $=$ $0.140)$, hypertension $(\mathrm{HTN})(\mathrm{P}$ value $=$ $0.465)$, smoking $(\mathrm{P}$ value $=0.87)$, family history $(\mathrm{P}$ value $=0.623)$ and dyslipidemia $(\mathrm{P}$ value $=0.482)($ Table 3 $)$.

Table (3): Comparison between normal and impaired RV function according to the age, sex and CV risk factors

\begin{tabular}{|c|c|c|c|c|}
\hline \multicolumn{2}{|c|}{$\mathrm{P}_{\text {Parameters }}$ Groups } & $\begin{array}{l}\text { Impaired RV } \\
\text { function } \\
(\mathbf{n}=\mathbf{2 2})\end{array}$ & $\begin{array}{l}\text { Normal RV } \\
\text { function } \\
(n=18)\end{array}$ & $P$ value \\
\hline \multirow{2}{*}{ Age } & Mean \pm SD & $55.59 \pm 9.87$ & $55.72 \pm 8.58$ & \multirow{2}{*}{0.938} \\
\hline & Range & $41-71$ & $40-73$ & \\
\hline \multirow{2}{*}{ Sex } & Male & $12(54.5 \%)$ & $12(66.7 \%)$ & \multirow{2}{*}{0.436} \\
\hline & Female & $10(45.5 \%)$ & $6(33.3 \%)$ & \\
\hline \multirow{5}{*}{$\begin{array}{c}\text { CV } \\
\text { RISK }\end{array}$} & DM & $19(86.4 \%)$ & $11(61.6 \%)$ & 0.140 \\
\hline & HTN & $15(68.2 \%)$ & $15(83.3 \%)$ & 0.465 \\
\hline & Smoking & $14(63.6 \%)$ & $11(61.1 \%)$ & 0.87 \\
\hline & Family history & $9(40.9 \%)$ & $6(33.3 \%)$ & 0.623 \\
\hline & Dyslipidemia & $11(50 \%)$ & $7(38.9 \%)$ & 0.482 \\
\hline
\end{tabular}

Different several echocardiographic LV parameters were compared in both groups including $\mathrm{LAD}(\mathrm{P}$ value $=0.743)$, LV EDD ( $\mathrm{P}$ value=0.327), LV ESD (P value $=0.375)$, LV EDV (P value $=0.427)$,
LV ESV (P value=0.081) and LV EF (P value $=0.071)$. However, both LV ESV and LV EF nearly reached a significance level in impaired RV function group (Table 4). 
Table (4): Comparison of echocardiographic findings in both groups of normal and impaired RV function groups

\begin{tabular}{|c|c|c|c|c|}
\hline \multicolumn{2}{|c|}{ Parameters $\quad$ Functions } & $\begin{array}{l}\text { Impaired RV } \\
\text { function group } \\
\quad(\mathbf{n}=\mathbf{2 2})\end{array}$ & $\begin{array}{c}\text { Normal RV } \\
\text { function group } \\
(\mathbf{n}=\mathbf{1 8})\end{array}$ & $\begin{array}{c}P \\
\text { value }\end{array}$ \\
\hline \multirow{2}{*}{$\mathrm{LAD}(\mathrm{mm})$} & Mean \pm SD & $37.05 \pm 2.89$ & $36.78 \pm 2.07$ & \multirow{2}{*}{0.743} \\
\hline & Range & $31-42$ & $33-40$ & \\
\hline \multirow{2}{*}{ LV EDD $(\mathrm{mm})$} & Mean \pm SD & $53.55 \pm 3.38$ & $52.56 \pm 2.81$ & \multirow{2}{*}{0.327} \\
\hline & Range & $48-59$ & $48-57$ & \\
\hline \multirow{2}{*}{ LV ESD (mm) } & Mean \pm SD & $30.09 \pm 8.01$ & $28.11 \pm 5.33$ & \multirow{2}{*}{0.375} \\
\hline & Range & $3-41$ & $23-39$ & \\
\hline \multirow{2}{*}{ LV EDV (ml) } & Mean \pm SD & $101.18 \pm 20.94$ & $96.56 \pm 13.88$ & \multirow{2}{*}{0.427} \\
\hline & Range & $60-139$ & $70-118$ & \\
\hline \multirow{2}{*}{ LV ESV (ml) } & Mean \pm SD & $59.64 \pm 13.96$ & $52.06 \pm 12.48$ & \multirow{2}{*}{0.081} \\
\hline & Range & $34-90$ & $34-76$ & \\
\hline \multirow{2}{*}{$\operatorname{LV}$ EF (\%) } & Mean \pm SD & $40.73 \pm 8.74$ & $46.11 \pm 9.55$ & \multirow{2}{*}{0.071} \\
\hline & Range & $25-52$ & $25-57$ & \\
\hline \multirow{2}{*}{$\begin{array}{l}\text { RV Dimensions } \\
(\mathrm{mm})\end{array}$} & Mean \pm SD & $29.95 \pm 2.97$ & $28.94 \pm 3.11$ & \multirow{2}{*}{0.302} \\
\hline & Range & $23-35$ & $21-34$ & \\
\hline \multirow{2}{*}{ RAA $(\mathrm{cm})$} & Mean \pm SD & $20.09 \pm 1.69$ & $19.83 \pm 1.62$ & \multirow{2}{*}{0.628} \\
\hline & Range & $18-24$ & $17-22$ & \\
\hline \multirow{2}{*}{ RVFAC (\%) } & Mean \pm SD & $32.45 \pm 1.77$ & $42.28 \pm 4.56$ & \multirow{2}{*}{$<0.001$} \\
\hline & Range & $30-35$ & $30-50$ & \\
\hline \multirow{2}{*}{ TAPSI (mm) } & Mean \pm SD & $15.14 \pm 1.28$ & $23.22 \pm 3.81$ & \multirow{2}{*}{$<0.001$} \\
\hline & Range & $13-17$ & $14-29$ & \\
\hline \multirow{2}{*}{ MPI (\%) } & Mean \pm SD & $52.27 \pm 1.61$ & $78.72 \pm 11.62$ & \multirow{2}{*}{$<0.001$} \\
\hline & Range & $49-55$ & $52-94$ & \\
\hline \multirow[b]{2}{*}{ s } & Mean \pm SD & $8.63 \pm 0.41$ & $9.94 \pm 0.36$ & \multirow{2}{*}{$<0.001$} \\
\hline & Range & $8-9.3$ & $9.5-11$ & \\
\hline
\end{tabular}

LCX affection was statistically associated with RV dysfunction than LAD. The incidence of significant lesion in LCX was high in RV impaired function group $(63.7 \%)$ compared to $11.1 \%$ in normal $\mathrm{RV}$ function group $(\mathrm{P}$ value $=$ 0.003) (Table 5). 
Table (5): Comparison between coronary angiographic findings in both normal and impaired RV function groups

\begin{tabular}{|c|c|c|c|c|}
\hline \multicolumn{2}{|l|}{ Parameters } & $\begin{array}{l}\text { Impaired RV } \\
\text { function group } \\
(\mathbf{n}=\mathbf{2 2})\end{array}$ & $\begin{array}{c}\text { Normal RV } \\
\text { function group } \\
(\mathrm{n}=\mathbf{1 8})\end{array}$ & $P$ value \\
\hline \multirow{5}{*}{ LAD lesion } & Proximal & $6(27.3 \%)$ & $7(38.9 \%)$ & \multirow{5}{*}{0.942} \\
\hline & Mid & $11(50 \%)$ & $7(38.9 \%)$ & \\
\hline & Proximal to mid & $1(4.5 \%)$ & $1(5.6 \%)$ & \\
\hline & Osteal & $3(13.6 \%)$ & $2(11.1 \%)$ & \\
\hline & Multiple lesions & $1(4.5 \%)$ & $1(5.6 \%)$ & \\
\hline \multirow{3}{*}{ LCX lesion } & Prox & $6(27.3 \%)$ & $1(5.6 \%)$ & \multirow{3}{*}{0.003} \\
\hline & Mid & $8(36.4 \%)$ & $1(5.6 \%)$ & \\
\hline & Non-significant lesion & $8(36.4 \%)$ & $16(88.9 \%)$ & \\
\hline \multirow{3}{*}{ DOMINANCE } & Yes & $7(31.8 \%)$ & $3(16.7 \%)$ & \multirow{3}{*}{0.053} \\
\hline & No & $15(68.2 \%)$ & $11(61.1 \%)$ & \\
\hline & Co & $0(0 \%)$ & $4(22.2 \%)$ & \\
\hline \multirow{3}{*}{ PCI } & $1 \mathrm{DES}$ & $12(54.5 \%)$ & $9(50 \%)$ & \multirow{3}{*}{0.275} \\
\hline & 2DES & $10(45.5 \%)$ & $7(38.9 \%)$ & \\
\hline & 3DES & $0(0 \%)$ & $2(11.1 \%)$ & \\
\hline
\end{tabular}

\section{DISCUSSION}

Right ventricular (RV) involvement after an acute left ventricular (LV) myocardial infarction (MI) has been shown to be associated with higher morbidity and mortality (Jensen et al., 2010). This current study exclusively included patients with anterior STEMI without concomitant RV infarction by ECG to assess RV function. 55\% of patients had impaired RV function.

In comparison to our results, some previous studies evaluated RV function after MI without RV infarction. Jensen and his Colleagues (2010) showed that $\mathrm{RV}$ involvement was diagnosed in $47 \%$ of cases with inferior STEMI and in $65 \%$ of cases with of cases with anterior STEMI. Masci and his Collagues (2010) concluded that early post infarction RV ischemic injury is common (approximately one-third to one-half of the patients) in patients without clinical evidence of hemodynamic RV compromise and is characterized by the presence of myocardial edema, late gadolinium enhancement, and functional abnormalities. RV injury is not limited to inferior infarcts but is commonly found in anterior infarcts as well. Kidawa et al. (2010) found that $64 \%$ of their patients had RV dysfunction measured by TAPSE. This higher incidence may be explained by the fact that they included all STEMI patients with possible occurrence of RV infarction in addition to the different assessment parameters.

We compared different echocardiographic parameters in patients with evidence of impaired RV function to those without. Several LV parameters were comparable in both groups including LAD, LV EDD, LV ESD, LV EDV, LV ESV and LVEF. However, both LV ESV and LV EF nearly reached a significance level.

In our study, we found that age of patients had no significant difference in both groups, which was supported by $\mathrm{Hsu}$ et al. (2013) who found no association 
between increasing age and the depressed RV function and abnormal MPI.

A study evaluated patients underwent successful reperfusion of a first episode of acute MI using echocardiography. At the acute phase of MI, RVEF, RVFAC and $\mathrm{RV}$, global strain were affected in both inferior and anterior MI but these parameters were lower inferior MI than in anterior MI (Huttin et al., 2015).

In patients with a first, acute reperfused STEMI without associated RV infarction, $\mathrm{RV}$ function may be affected discrepantly depending on the different infarction sites. In patients with inferior infarction without concomitant RV infarction, only regional RV diastolic dysfunction is observed, whereas the alteration of global RV function is more pronounced in patients with anterior wall infarction (Hsu et al., 2011). The anterior portion of the RV has a dual coronary blood supply that consists of RV branches from the LAD coronary artery and the conus branch of the RCA. So, it is supposed that RCA ensure blood supply to the right ventricle in cases of anterior LV infarction. But our study highlights RV dysfunction could develop in anterior MI.

Additionally, we found that LCX affection was statistically associated with RV dysfunction than LAD. The incidence of non-significant lesion in LCX was lower in RV impaired function group (36.4\%) compared to $88.9 \%$ in normal RV function group.

Our findings were not affected by underlying confounding patients related factors, both impaired and normal RV function groups were not statistically different in terms of age, gender, DM,
HTN, smoking, family history and dyslipidemia.

\section{CONCLUSION}

$\mathrm{RV}$ dysfunction was detected in anterior myocardial infarction after successful revascularization. Several echocardiographic parameters may be possible measures for $\mathrm{RV}$ dysfunction including RVFAC, TAPSI, MPI and S'.

\section{REFERENCES}

1. Hsu Y, Jeng F and Shan-H. (2011): Right ventricular function in patients with different infarction sites after a first acute myocardial infarction. Am J Med Sci, 342, 474-9.

2. Hsu Y, Chang H, Liu J, Lin F, Ko and Cheng T. (2013): Correlates of impaired global right ventricular function in patients with reperfused acute myocardial infarction and without right ventricular infarction. J Investig Med., 61:715-721.

3. Huttin O, Jérémie L, Marine D. M, Nicolas G, Damien M, Frédéric $M$, Simon L, Yves J, Jacques F, Pierre $Y \quad M$ and Christine S. (2015): Assessment of right ventricular functional recovery after acute myocardial infarction by $2 \mathrm{D}$ speckletracking echocardiography. Int $\mathbf{J}$ Cardiovasc Imaging, 31, 537-45.

4. Jensen C J., Markus J, Peter H, Georg V. S, Thomas S and Oliver B. (2010): Right ventricular involvement in acute left ventricular myocardial infarction: prognostic implications of MRI findings. AJR Am J Roentgenol, 194, 592-8.

5. Kidawa M, Kasprzak J, Wierzchowski T and Krzeminska P. 
(2010): Right ventricular function suffers from reperfusion delay: tissue Doppler study. Clin Cardiol., 33:E438.

6. Lang M., Bierig M., Devereux B., Flachskampf A., Foster E. and Pellikka A. (2005): Recommendations for chamber quantification: a report from the American Society of Echocardiography's Guidelines and Standards Committee and the Chamber Quantification Writing Group, developed in conjunction with the European Association of Echocardiography, a branch of the European Society of Cardiology. J Am Soc Echocardiogr, 18: 1440-63.

7. Masci G, Marco F, Walter D, Javier G, Giancarlo T, Rocco D, Valeria S,
Iacopo C, Matteo M, Elisabetta S, Carlo C, Massimo L, Luciano A, Stefan J and Jan B. (2010): Right ventricular ischemic injury in patients with acute ST-segment elevation myocardial infarction: characterization with cardiovascular magnetic resonance. Circulation, 122: 1405-12.

8. Rudski L, Lai W, Afilalo J, Hua L, Handschumacher $M$ and Chandrasekaran K. (2010): Guidelines for the echocardiographic assessment of the right heart in adults. J Am Soc Echocardiogr, 23: 685-713; quiz 786-8.

9. Thygesen K, Alpert J, Jaffe A, Simoons M, Chaitman B and White H. (2012): Third universal definition of myocardial infarction. Eur Heart J, 33: 2551-67. 


\section{تقييم وظيفة البطين الأيمن بالموجات فوق الصوتية ثنائية الأبعاد في مرضىى احتثاء عضلة القلب الأمامي بعد التروية باتية الناجحة}

محمد السيد حماد*، محمد سامي عبدالسميع**، عبدالمحسن مصطقى عبده* قسم القلب والأوعية الاموية، كلية الطب، جامعة الأزهر

E-mail: $\underline{\text { ma102416@gmail.com }}$

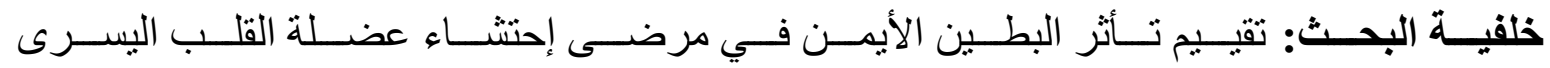

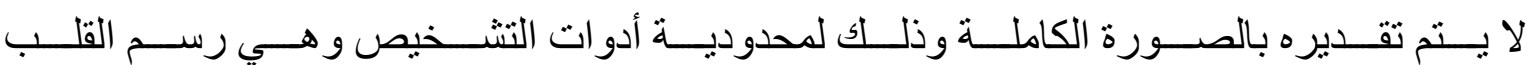
و الموجات الصوتية.

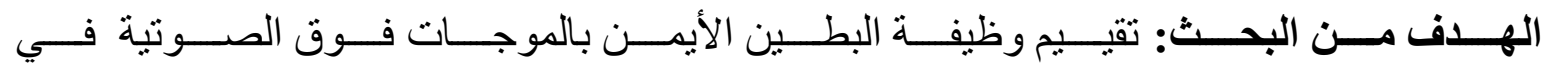
مرضى احتشاء عضلة القلب الأمامي بعد التروية الناجحة و العو امل المؤثرة عليه.

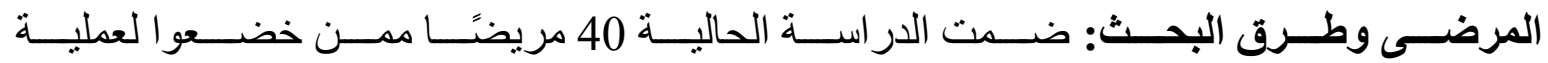

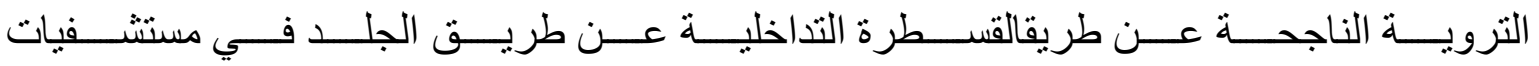

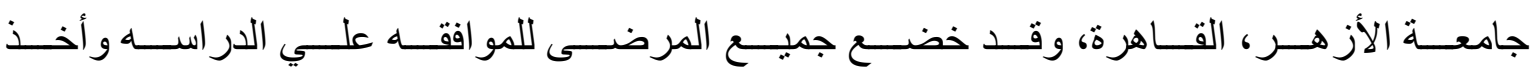

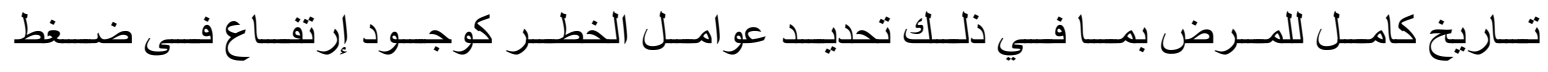

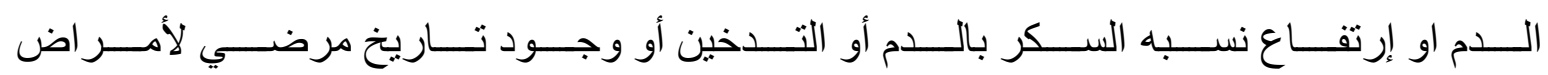

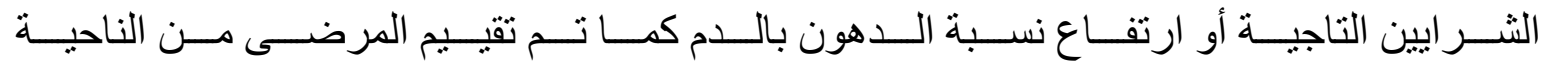

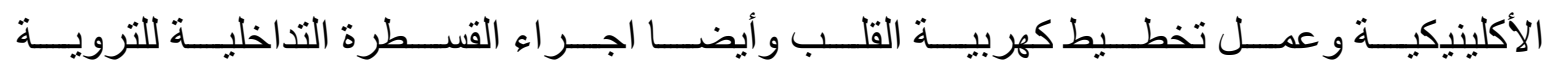

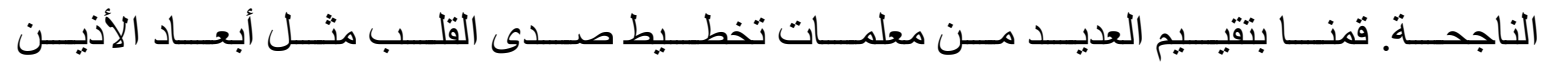

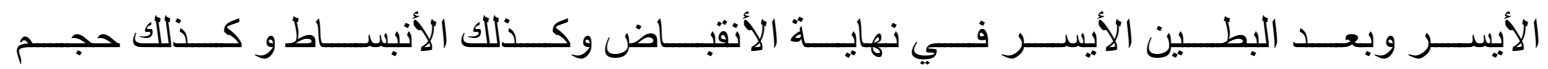

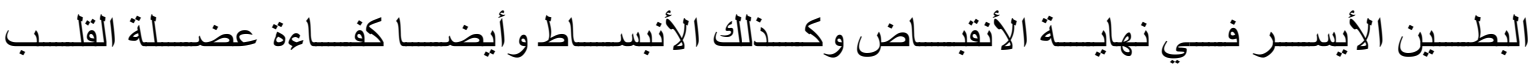

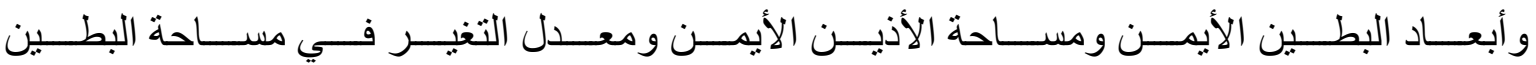

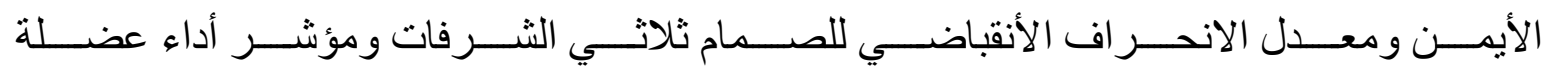

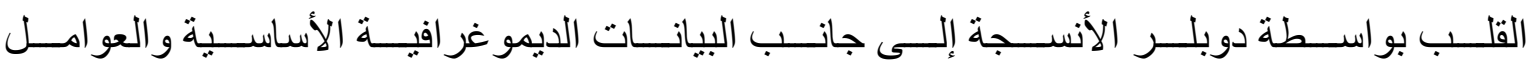
المشتركة. 


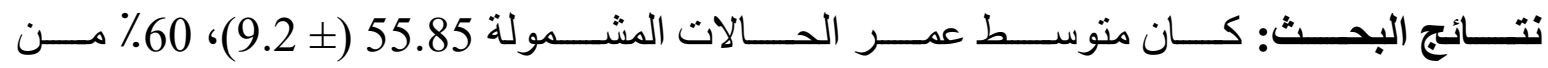

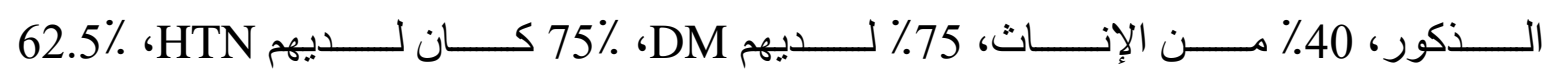

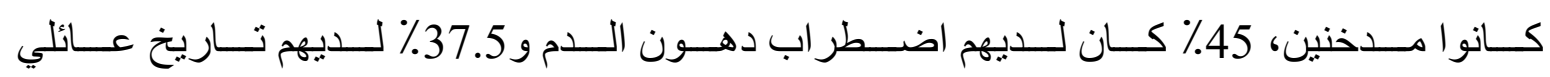

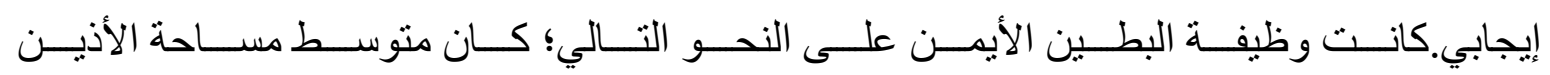

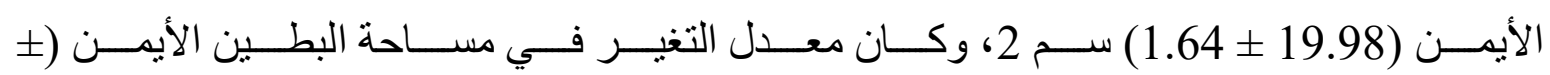

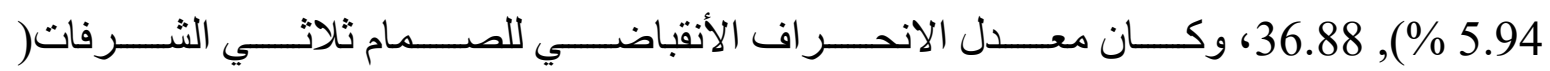

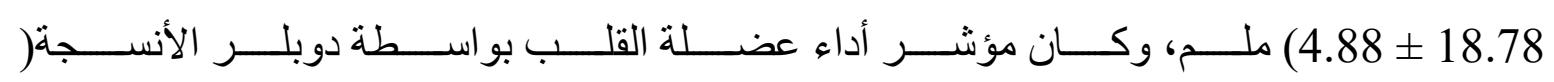

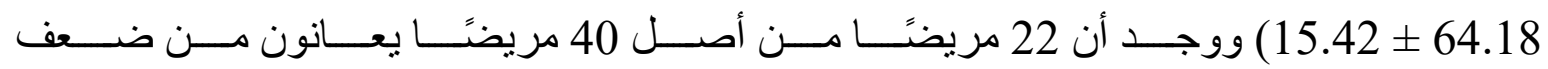

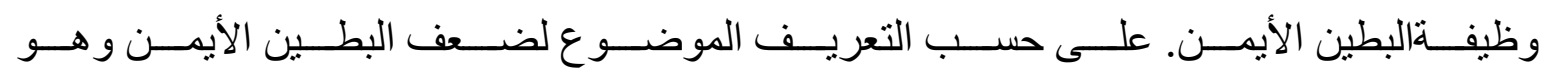

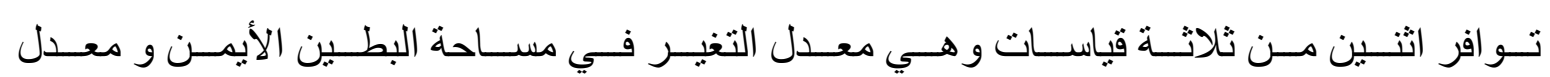

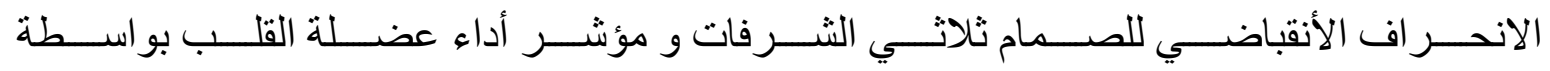
دوبلر الأنسجة.

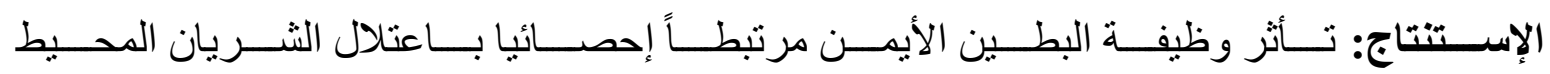

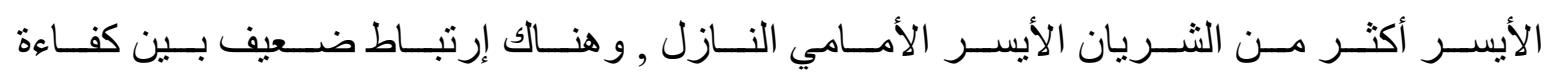
عضلة القلب اليسرى وإعتلال البطين الأيمن.

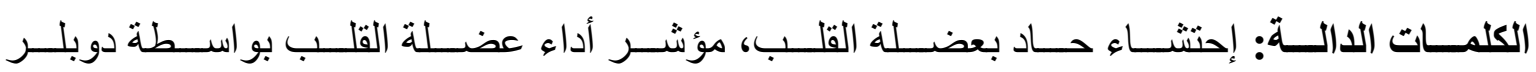

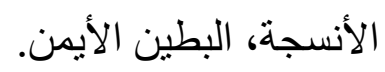

